\title{
IS EPISTOCRACY IRRATIONAL?
}

\author{
Adam F. Gibbons
}

II

T IS COMMONLY THOUGHT that widespread voter ignorance is a problem for democracies. ${ }^{1}$ Ignorant voters can inadvertently vote against their interests. More generally, political leaders can supply harmful laws and policies by catering to the ill-informed preferences of such voters. If the electorate wants bad policies, accommodating politicians will often satisfy their demands. Epistocrats think that we should mitigate the harm caused by voter ignorance by allocating comparatively greater amounts of political power to citizens who possess more politically relevant knowledge. ${ }^{2}$

One important challenge to epistocracy attacks the underlying assumption that better-informed citizens possess superior political judgment. ${ }^{3}$ According to this challenge, while better-informed citizens may possess more knowledge of politically relevant facts, much research in political psychology indicates that better-informed citizens are less rational than their ill-informed counterparts, being more susceptible to various biases, more partisan, less open minded, and more prone to engaging in motivated reasoning. Correlatively, their ill-informed counterparts are less biased, less partisan, more open minded, and engage in motivated reasoning with less frequency. ${ }^{4}$ Epistocratic institutions, then, might

1 Caplan, The Myth of the Rational Voter; Somin, Democracy and Political Ignorance; and Brennan, Against Democracy.

2 Brennan, Against Democracy; and Jones, 10\% Less Democracy.

3 Friedman, "Democratic Competence in Normative and Positive Theory"; Gunn, "Against Epistocracy”; Hannon, "Are Knowledgeable Voters Better Voters?"

4 Box-Steffensmeier and De Boef, "Macropartisanship and Macroideology in the Sophisticated Electorate"; Zaller, "Floating Voters in U.S. Presidential Elections, 1948-2000"; Achen and Bartels, "Blind Retrospection"; Taber and Lodge, "Motivated Skepticism in the Evaluation of Political Beliefs"; Abramowitz and Saunders, "Is Polarization a Myth?"; Taber, Cann, and Kucsova, "The Motivated Processing of Political Arguments"; Hartman and Newmark, "Motivated Reasoning, Political Sophistication, and Associations between President Obama and Islam"; Joslyn and Haider-Markel, "Who Knows Best?"; Lodge and Taber, The Rationalizing Voter; Kahan, Peters, Dawson, and Slovic, "Motivated Numeracy and Enlightened Self-Government"; and Guay and Johnston, "Ideological Asymmetries and the Determinants of Politically Motivated Reasoning." 
just end up placing more political power in the hands of less rational citizens. There is no guarantee that such institutions would constitute an improvement over existing democratic institutions, and they may even lead to worse governance and worse outcomes. ${ }^{5}$ Call this the problem of epistocratic irrationality.

In this paper I argue that the problem of epistocratic irrationality can be overcome. A closer look at the psychological data adverted to by critics of epistocracy shows that it is unclear whether it has the implications such critics claim it has. But even if the critics are right about these implications, it still would not follow that democratic institutions will outperform epistocratic institutions. Much depends on the precise form that the envisaged epistocratic institutions take. A more considered approach to epistocratic institutional design might allow us to reap the benefits of placing more power in the hands of the more knowledgeable, while avoiding some of the costs associated with increasing the power of purportedly more dogmatic citizens.

I begin in section 1 by outlining the problem that voter ignorance presents to democracy, before then discussing the problem of epistocratic irrationality at greater length. In section 2, I argue that critics of epistocracy have downplayed and overlooked several problems with their arguments for epistocratic irrationality. First, the citizens counted as knowledgeable by the standards of the experiments that critics advert to are not always such that they would be knowledgeable according to epistocratic standards. Second, the relationship between levels of political knowledge and political irrationality revealed by such experiments is often more complex than critics of epistocracy suppose. Third, the value of traits such as open mindedness is easy to exaggerate. Even if less politically knowledgeable people were more open minded (and more knowledgeable people less open minded), it is unclear whether this would have the upshots attributed to it by critics of epistocracy. In section 3, I argue that even if the relevant data has the implications that critics claim it has, suitably amended forms of epistocracy could overcome the problem of epistocratic irrationality. I consider two potential strategies: (1) using refined selection mechanisms that avoid placing too much power in the hands of irrational citizens, and (2) increasing epistocratic influence only in those areas where such influence has a reliable track record of improving outcomes. I turn to consider some objections to my claims in section 4 . Section 5 concludes by summarizing the main claims of the paper.

5 What it is to govern well is naturally a controversial question. In this paper, I focus solely on the relative epistemic merits of democratic institutions as against epistocratic institutionsthat is, I focus on the degree to which such institutions (attempt to) create legislation grounded in objective facts, the degree to which such institutions use reliable decision-making methods, and the like. 


\section{DEMOCRATIC IGNORANCE AND EPISTOCRATIC IRRATIONALITY}

The claim that a well-informed population is central to the health of a democracy is widely endorsed. ${ }^{6}$ An uninformed population may not know which policies are in their best interests. An uninformed population cannot hold their representatives meaningfully accountable. ${ }^{7}$ Even epistemic democrats, sanguine as they are about individually ignorant voters, accept that a minimum level of voter competence is a necessary precondition of an epistemically well-functioning democracy. ${ }^{8}$

However, many decades of empirical studies indicate that most voters are ignorant of even basic political facts. ${ }^{9}$ Not only are voters unfamiliar with simple, relatively uncontroversial findings in economics, political science, and other social sciences, they often do not know basic facts such as which politicians were responsible for enacting certain pieces of legislation, what sorts of policies are favored by candidates for office, the various roles played by different political agents and organizations, the identities of their representatives, and so on. If a well-informed population is central to the health of democracies, and if most voters are politically ignorant, then democracies face a serious problem. A necessary condition of a flourishing democracy is seemingly unsatisfied.

What, if anything, should be done to mitigate the harm caused by voter ignorance? Epistocrats think that we should allocate more formal political power to those citizens who possess more knowledge of politically relevant facts. ${ }^{10}$ In effect, the harm caused by voter ignorance cannot be mitigated without transitioning away from democratic institutions to some extent. Epistocratic reforms variously try to ensure that only politically knowledgeable people possess political power, or that the political power of politically knowledgeable people is

6 Mill, Considerations on Representative Government, ch. 2; Dewey, Democracy and Education; and Gutmann, Democratic Education.

7 Gutmann and Thomson, Why Deliberative Democracy? 35; and Guerrero, "Against Elections."

8 Landemore, Democratic Reason; and Goodin and Spiekermann, An Epistemic Theory of Democracy.

9 For helpful overviews of the relevant literature, see Caplan, The Myth of the Rational Voter; Oppenheimer and Edwards, Democracy Despite Itself; Somin, Democracy and Political Ignorance; and Brennan, Against Democracy.

Brennan, Against Democracy; Mulligan, "Plural Voting for the 21st Century"; Jones, 10\% Less Democracy; Malcolm, "Epistocracy and Public Interests." By "formal" I mean the sort of political power allocated to one by virtue of some law or institution. The political power granted to one by virtue of a legal right to vote is a paradigmatic example of such power, as are the sort of powers one gains upon occupying certain political offices (such as the various powers associated with being a member of the upper and lower houses of parliaments, the executive branch, and so forth). 
amplified relative to less knowledgeable people. Ideally, such reforms would increase the degree to which political decision-making is based upon objective, politically relevant facts.

A seemingly unquestioned assumption underlying arguments for epistocracy is the claim that greater levels of political knowledge confer superior political judgment. But this might be mistaken. Suitable levels of political knowledge are not the only thing central to the health of a well-functioning polity. In addition to well-informed citizens, we also need citizens who are rational. ${ }^{11}$ We need citizens who are willing to appropriately update their beliefs in response to new evidence. We need citizens who can set aside partisan loyalties when it becomes clear that these loyalties lead them astray. We need citizens who are open minded and undogmatic. Knowing what the available evidence indicates on politically relevant issues is, of course, deeply important. But a stubborn resistance to following new evidence can be quite damaging in its own right. Broadly speaking, such resistance might cause us to stick with the status quo even if the available evidence indicates that it is harmful. This has important upshots for the viability of epistocracy. If more knowledgeable citizens are less rational, then it becomes unclear whether epistocratic institutions will yield the benefits ascribed to them by proponents of epistocracy. Epistocratic institutions might solve one problem at the cost of another. ${ }^{12}$

Several critics of epistocracy contend that this is precisely what the available evidence from political psychology shows. ${ }^{13}$ They claim that since more knowledgeable citizens are more partisan and less rational than their less knowledgeable peers, epistocratic reforms may produce even worse outcomes than the existing democratic institutions they are intended to supplant. This is a power-

By "rational" here I have in mind epistemic rationality. We need citizens who are both well-informed and who behave in paradigmatically epistemically rational ways when reasoning about political matters. Epistemically irrational conduct may or may not be instrumentally rational for some citizens.

An independent problem facing epistocracy stems from the recognition that, in principle, the individually ignorant citizens empowered by democratic institutions might make collectively wise decisions, while the well-informed citizens empowered by epistocratic institutions might make collectively unwise decisions. In short, individual and collective intelligence sometimes pull apart. Since this issue has been extensively discussed elsewhere, I set it aside in this paper, though I note the complications it raises for discussions of the comparative epistemic merits of democracies and epistocracies (Surowiecki, The Wisdom of Crowds; Landemore, Democratic Reason; Goodin and Spiekermann, An Epistemic Theory of Democracy). I consider a variant of this problem, one involving individual and collective rationality, in section 4 .

13 Friedman, "Democratic Competence in Normative and Positive Theory"; Gunn, "Against Epistocracy"; and Hannon, "Are Knowledgeable Voters Better Voters?" 
ful challenge that proponents of epistocracy ought to take seriously, for if these critics are correct then the prospects for epistocracy are dim.

There is much evidence indicating that more knowledgeable citizens are also more partisan than their ill-informed peers. ${ }^{14}$ The more one knows about politics, the more likely one is to be strongly allied to certain views or politicians while strongly opposed to others. Indeed, the causal direction is often the reverse-people more interested in politics and more allied to certain views will generally tend to acquire more political information. But high levels of partisanship create problems. Michael Hannon puts it well when he writes:

The problem ... is that the most politically partisan individuals (who are also the most knowledgeable, remember) are also the most likely to have their thinking corrupted by politics. ${ }^{15}$

In a similar vein, Paul Gunn, drawing on the seminal work of Philip Converse, notes that "the more political knowledge people possess, the more 'constrained' by ideology they tend to be." ${ }^{16}$

It is worth understanding why more partisan individuals tend to have their thinking corrupted by politics more often (and more severely) than less partisan individuals. In general, heavily partisan individuals are more likely to possess a self-conception defined in part by their adherence to certain political beliefs. ${ }^{17}$ If one were to ask such partisan individuals to describe themselves, they might reply by saying that they are, for instance, a supporter of the second amendment, a fiscal conservative, or something to that effect. These beliefs are a core part of their identity (as they see it). Importantly, however, a body of research in political and cognitive psychology shows that such individuals are more prone to engaging in motivated reasoning. ${ }^{18}$ Partisans engaged in motivated reasoning are more likely to actively seek out evidence that confirms their preferred views, more likely to unquestioningly accept evidence that supports their views, more

14 Judd and Brauer, "Repetition and Evaluative Extremity"; Box-Steffensmeier and De Boef, "Macropartisanship and Macroideology in the Sophisticated Electorate"; Zaller, "Floating Voters in U.S. Presidential Elections, 1948-2000"; Abramowitz and Saunders, "Is Polarization a Myth?"; Feldman and Price, "Confusion or Enlightenment?"; Hetherington, "Putting Polarization in Perspective”; Joslyn and Haider-Markel, "Who Knows Best?”; and Kalmoe, "Uses and Abuses of Ideology in Political Psychology." Hannon, "Are Knowledgeable Voters Better Voters?” 3.

16 Gunn, "Against Epistocracy," 35. Gunn here cites Converse, “The Nature of Belief Systems in Mass Publics," 213. See also Friedman, Power without Knowledge. Haidt, The Righteous Mind. Hannon calls such beliefs identity-constitutive beliefs ("Are Knowledgeable Voters Better Voters?” 3 ).

Kunda, "The Case for Motivated Reasoning." 
likely to avoid evidence that conflicts with their views, more likely to be disproportionately critical of opposing evidence, and so on. ${ }^{19}$ In short, partisans are biased toward conclusions they like and biased against conclusions they dislike. Rather than dispassionately assessing the relevant evidence, partisans press their cognitive abilities into the service of protecting their core political beliefs.

Partisans, then, engage in motivated reasoning more frequently than nonpartisans because political beliefs form a central part of their self-conception, which they are strongly motivated to defend. ${ }^{20}$ The problem for epistocracy becomes clear. Epistocratic institutions would enhance the political power of more knowledgeable citizens relative to their less knowledgeable peers. But these more knowledgeable citizens also happen to be much more partisan than others. Since they are partisan, they will engage in the sort of corrupted thinking outlined above - they will dismiss ideologically inconvenient data, they will rush to conclusions that fit their preconceptions, they will selectively focus their critical attention onto views they dislike, and so on. ${ }^{21}$ By attempting to empower the more knowledgeable among us, epistocracy will also empower those of us who most deeply exemplify a host of problematic epistemic vices. Political ignorance may indeed be a problem worth fixing, but the proposed epistocratic cure may end up worse than the illness, for it is not obvious that amplifying the political power of more partisan, less rational citizens is a reliable way to secure better policies and better outcomes.

\section{HOW SERIOUS IS THE PROBLEM OF EPISTOCRATIC IRRATIONALITY?}

The problem of epistocratic irrationality highlights a weakness in extant epistocratic proposals. By focusing too much on what voters know and not enough on how voters update their beliefs in light of new evidence, epistocratic reforms risk

Taber and Lodge, "Motivated Skepticism in the Evaluation of Political Beliefs"; Taber, Cann, and Kucsova, "The Motivated Processing of Political Arguments"; Hartman and Newmark, "Motivated Reasoning, Political Sophistication, and Associations between President Obama and Islam"; Lodge and Taber, The Rationalizing Voter; Bolsen, Druckman, and Cook, "The Influence of Partisan Motivated Reasoning on Public Opinion”; Kuru, Pasek, and Traugott, "Motivated Reasoning in the Perceived Credibility of Public Opinion Polls"; Guay and Johnston, "Ideological Asymmetries and the Determinants of Politically Motivated Reasoning"; and Vegetti and Mancosu, "The Impact of Political Sophistication and Motivated Reasoning on Misinformation.”

Kahan, "Misconceptions, Misinformation, and the Logic of Identity-Protective Cognition"; Kahan, Peters, Dawson, and Slovic, "Motivated Numeracy and Enlightened Self-Government”; and Mason, Uncivil Agreement. 
placing too much power in the hands of citizens who, through their epistemic vices, would often make bad decisions. It is therefore unclear whether such reforms would constitute an improvement over existing democratic institutions.

However, it is important to bear in mind the following caveat regarding the problem of epistocratic irrationality: even if critics of epistocracy are right to claim that the data from political psychology shows that more knowledgeable citizens are typically less rational than their less knowledgeable peers, such data cannot by itself establish that democratic institutions will outperform epistocratic institutions along various dimensions. To establish the superiority of existing democratic institutions would require a serious empirical analysis of the performance of both sorts of institutions. This in turn would require investigating, inter alia, the impacts of ignorant voters on policy outcomes compared to the impacts of more knowledgeable but less rational voters. Then this would require an analysis of the importance of the issues that less knowledgeable voters are typically ignorant of, the sorts of issues more dogmatic voters are typically reluctant to change their minds about, the degree to which legislators and policymakers are responsive to both groups of voters, and more. In short, psychological data of the sort appealed to by critics of epistocracy cannot furnish us with evidence regarding the overall costs and benefits of both sets of institutions. Instead, we would need to measure the actual performance of democratic institutions against epistocratic ones.

In response, one might think that critics of epistocracy do not intend to show that the overall costs of epistocracy will outweigh its benefits, or that democratic institutions are superior to epistocratic ones. Instead, one might think that they intend only to undercut the claim that epistocratic institutions would be superior to democratic ones, and that they do so successfully. ${ }^{22}$ Perhaps it is true that critics of epistocracy intend to offer only undercutting evidence. Nonetheless, this is consistent with thinking that the ultimate test of epistocracy consists in implementing different epistocratic institutions and measuring their subsequent performance along various parameters, comparing such performance to the performance of democratic alternatives. For those willing to experiment with novel institutional arrangements, this is important. Additionally, in what follows I show that the critics have failed to successfully undercut the case for epistocracy. In this section I discuss some complications with the interpretation of the relevant psychological data critics defend, arguing that these complications should undermine our confidence in such an interpretation. In the following section I discuss certain classes of epistocratic institutions that can overcome the prob- 
lem of epistocratic irrationality even if critics of epistocracy have correctly interpreted the relevant psychological data.

Regarding the former, what sort of complications do I have in mind?

\subsection{Who Counts as Knowledgeable?}

First, critics of epistocracy frame the relevant studies as showing that more knowledgeable citizens are typically less rational than their ill-informed counterparts. But this description of the data is underspecified. With this information alone we do not know, for example, in what way the subjects of the experiments are knowledgeable, or whether such subjects would count as knowledgeable according to the standards of different epistocratic proposals. Without knowing whether the subjects of the experiments are the sort of people who would be disproportionately empowered by epistocratic mechanisms, we cannot know whether these studies in fact present a problem for epistocracy. In effect, we cannot know whether there really is a problem of epistocratic irrationality-at least, that is, for certain forms of epistocracy.

Consider, for example, the work of Lodge and Taber on motivated political reasoning. ${ }^{23}$ Critics of epistocracy point to this work as evidence of the claim that more knowledgeable citizens are more prone to motivated political reasoning than less knowledgeable citizens. ${ }^{24}$ Lodge and Taber do indeed find evidence of what they call a sophistication effect, wherein more knowledgeable citizens_-sophisticates - are more prone to engaging in motivated reasoning. ${ }^{25}$ More specifically, more knowledgeable citizens more frequently exhibit both confirmation bias (by willingly seeking out confirming arguments rather than disconfirming arguments) and disconfirmation bias (by spending more time and energy challenging attitudinally incongruent arguments than they do on attitudinally congruent arguments). ${ }^{26}$ Additionally, sophisticates polarize in their beliefs to a greater degree than non-sophisticates. ${ }^{27}$ However, it is worth noting that the subjects of their experiments were classed as sophisticates depending on how well they scored on a general political knowledge scale consisting of sev-

23 Taber and Lodge, "Motivated Skepticism in the Evaluation of Political Beliefs"; and Lodge and Taber, The Rationalizing Voter.

24 Gunn, "Against Epistocracy"; and Hannon, "Are Knowledgeable Voters Better Voters?"

25 They also find evidence for what they call an attitude strength effect, where those citizens with the strongest policy attitudes are most prone to politically motivated reasoning (Lodge and Taber, The Rationalizing Voter, 153).

For an overview of the evidence they adduce in support of these claims, see Lodge and Taber, The Rationalizing Voter, 158-67.

Lodge and Taber, The Rationalizing Voter, 168. 
enteen items, including questions like "What proportion of Congress is needed to override a presidential veto?" ${ }^{28}$ Notably, Lodge and Taber use a median split to differentiate sophisticates from non-sophisticates.

Similar measures of political knowledge are used in other studies purporting to show that more knowledgeable citizens engage in politically motivated reasoning more often than their less knowledgeable peers. Consider the work of Kuru, Pasek, and Traugott showing that more knowledgeable citizens are more prone to politically motivated reasoning about the results of public opinion polls, or the work of Vegetti and Mancosu showing that more knowledgeable citizens are prone to politically motivated reasoning about various news items. ${ }^{29}$ The former measures political knowledge using five multiple-choice questions regarding recent news events. ${ }^{30}$ The latter, using a sample of Italian citizens, measures political knowledge using three questions regarding the identity of the president of the Republic, the president of the Low Chamber, and the number of deputies in the Low Chamber. ${ }^{31}$

Are these sophisticates the sort of people who would possess more political power under epistocratic institutions? Naturally, the answer varies when different forms of epistocracy are considered. On some forms of epistocracy, the

28 Taber and Lodge, "Motivated Skepticism in the Evaluation of Political Beliefs," 760; Lodge and Taber, The Rationalizing Voter, 84.

29 Kuru, Pasek, and Traugott, "Motivated Reasoning in the Perceived Credibility of Public Opinion Polls"; Vegetti and Mancosu, "The Impact of Political Sophistication and Motivated Reasoning on Misinformation."

30 Kuru, Pasek, and Traugott, "Motivated Reasoning in the Perceived Credibility of Public Opinion Polls," 431.

31 Vegetti and Mancosu, "The Impact of Political Sophistication and Motivated Reasoning on Misinformation," 7-8. Indeed, such measures are pervasive in the literature on the relationship between levels of political knowledge, partisanship, and politically motivated reasoning. Virtually every study either uses their own general knowledge scale (Judd and Brauer, "Repetition and Evaluative Extremity"; Box-Steffensmeier and De Boef, "Macropartisanship and Macroideology in the Sophisticated Electorate"; Federico, "Predicting Attitude Extremity”; Feldman and Price, "Confusion or Enlightenment?"; Hetherington, "Putting Polarization in Perspective"; Taber, Cann, and Kucsova, "The Motivated Processing of Political Arguments"; Hartman and Newmark, "Motivated Reasoning, Political Sophistication, and Associations between President Obama and Islam"; Joslyn and Haider-Markel, "Who Knows Best?"; Bolsen, Druckman, and Cook, “The Influence of Partisan Motivated Reasoning on Public Opinion"; Guay and Johnston, "Ideological Asymmetries and the Determinants of Politically Motivated Reasoning") or relies upon data from sources such as reports from American National Election Studies (Zaller, "Floating Voters in U.S. Presidential Elections, 1948-2000"; Abramowitz and Saunders, "Is Polarization a Myth?"; Bartels, Unequal Democracy; Kalmoe, "Uses and Abuses of Ideology in Political Psychology"). In either case, levels of political knowledge are gauged using relatively low numbers of general knowledge items. 
class of sophisticates plausibly more or less aligns with the class of those citizens whose political power would be amplified. A scheme of restricted suffrage deploying minimally demanding voter-qualification exams that test for general political knowledge might be adversely impacted by the findings adduced by critics of epistocracy. ${ }^{32}$ The same applies to any form of epistocracy allocating more political power to those who possess more knowledge of these basic and general political facts alone. ${ }^{33}$ But other forms of epistocracy with more demanding standards might escape the challenge of epistocratic irrationality altogether. For instance, under veto council epistocracy, a select group of extremely knowledgeable citizens would constitute an epistocratic council tasked with vetoing potentially harmful laws and policies. ${ }^{34}$ Acquaintance with only basic questions of general political knowledge would not grant one access to such an institution. Instead, one must possess considerable levels of knowledge of - and perhaps even expertise in - one of several fields, such as economics, sociology, or political science. The experiments pointed to by critics of epistocracy do not establish that such citizens are more prone to engaging in motivated reasoning. Accordingly, forms of epistocracy using similarly demanding qualifications are not obviously subject to the problem of epistocratic irrationality. ${ }^{35}$

One might grant this point while denying its significance. In the absence of evidence that the sort of citizens who would satisfy extremely demanding qualification requirements behave more rationally than either the citizens identified as sophisticates in the psychological literature or non-sophisticates, why grant such an assumption? Until such evidence is supplied, the importance of the relevant mismatch in standards of knowledge is unclear at best.

This point should be conceded. Still, it is important to recognize that the available data does not say much about citizens that we might call extreme sophisticates - that is, citizens who cannot only answer several basic general knowledge items, but who additionally possess considerable knowledge of the structure and function of existing political institutions, economics, political science, sociology, and more. It is at least possible that such citizens, outliers as they al-

On restricted suffrage, see Brennan, Against Democracy, 211-14.

33

For a discussion of minimal epistocracy - a form of epistocracy restricting itself only to uncontroversial, basic political facts — see Gibbons, "Political Disagreement and Minimal Epistocracy." Whether they are or not is clearly an empirical question. I only claim that the studies adverted to by critics of epistocracy do not establish that they are in fact so harmed. 
ready are in the degree to which they are well-informed about politically relevant matters, may differ in how they reason about politics compared to other citizens.

Moreover, there is some suggestive evidence that the most well-informed citizens (as measured by the typical scales deployed by political psychologists) can resist partisan influences better than their less knowledgeable peers. ${ }^{36} \mathrm{Con}$ sequently, the fact that different forms of epistocracy deploy different measures of knowledge may indeed be important as far as the problem of epistocratic irrationality is concerned.

\subsection{What Is the Relationship between Political Knowledge and Political Rationality?}

Second, critics of epistocracy sometimes characterize the relevant data as showing that higher levels of knowledge positively correlate with a greater propensity to engage in motivated reasoning, adoption of more extreme views, more closemindedness, and so on. In contrast to more knowledgeable citizens, less knowledgeable citizens are more open minded, less prone to engaging in motivated reasoning, and the like. For instance, in describing the relevant psychological findings, Gunn writes that "these effects tend to occur more frequently and stubbornly among citizens who are relatively well informed than among those citizens who are not." ${ }^{\text {"7 }}$ This description of the data is not inaccurate, but it omits crucial details, oversimplifying the relationship between levels of political knowledge, political irrationality, and other independent traits. Indeed, the relevant data is oversimplified in at least two important ways.

On the one hand, such a presentation of the psychological findings overlooks the possibility that other factors might be driving both the acquisition of political knowledge and motivated reasoning. Indeed, for many individuals, the key point is that they are motivated (perhaps because they are independently partisan) and not that they know more. ${ }^{38}$ As Taber and Lodge write:

[Our] theory predicts less bias for unsophisticated and uncommitted respondents not because they possess a greater sense of evenhandedness, but rather because they lack the motivation and ability to engage in attitude defense. ${ }^{39}$

36 Achen and Bartels, "It Feels Like We're Thinking," 16, 21. Interestingly, Hannon also acknowledges the fact that the most well-informed citizens may be more rational than merely moderately well-informed citizens ("Are Knowledgeable Voters Better Voters?" 14).

37 Gunn, "Against Epistocracy," 42.

38 To his credit, Hannon acknowledges this point, writing that "it may be that increasing political knowledge is counterproductive only when it occurs in partisan individuals" (Are Knowledgeable Voters Better Voters?” 5).

39 Taber and Lodge, "Motivated Skepticism in the Evaluation of Political Beliefs," 767. 
In short, ill-informed citizens are less epistemically virtuous than they are unmotivated, and it is the motivation of knowledgeable citizens that drives politically motivated reasoning, not the acquisition of facts per se. Similarly, some studies find that other traits that sometimes (though not always) correlate with high levels of knowledge are what drive attitude extremity. For instance, Federico argues that a high need to evaluate - a felt need to assess things for positive and negative qualities - is what drives attitude extremity, not high levels of knowledge. ${ }^{40}$

Of course, this by itself does not show that critics of epistocracy are mistaken to highlight the importance of the correlation between high levels of political knowledge and political irrationality. If a tendency to engage in politically motivated reasoning correlates with levels of political knowledge, then epistocratic institutions may encounter a problem of irrationality even if the relevant relationship is not causal. For the problem of epistocratic irrationality to emerge, it is enough that epistocratic institutions disproportionately empower epistemically vicious citizens. Still, as we will see in section 3, the absence of a causal relationship paves the way for more refined epistocratic selection mechanisms that can identify (and subsequently empower) well-informed individuals without thereby empowering irrational individuals.

On the other hand, it should be noted that such a presentation of the data masks the considerable variety one can find among both well-informed and ill-informed citizens. To be sure, the data does indeed indicate that moderately knowledgeable citizens are in general less rational than less knowledgeable citizens. However, the gap between these two groups vanishes regarding certain issues. ${ }^{41}$ Further, Vegetti and Mancosu argue that more knowledgeable citizens are less susceptible to character-related misinformation than knowledgeable citizens. ${ }^{42}$ Again, Taber and Lodge put it best when they explicitly caution against taking their findings to show that less knowledgeable citizens are free from epistemic vice:

Provocative though it may be, this interpretation does not stand up to normative, theoretical, or empirical scrutiny.... We find no empirical evidence of principled moderation among the bottom or middle thirds of our sample, whose extremity scores were statistically indistinguishable from those of the most sophisticated participants. ${ }^{43}$

Federico, "Predicting Attitude Extremity," 1287. On the need to evaluate, see Jarvis and Petty, "The Need to Evaluate."

Taber and Lodge, "Motivated Skepticism in the Evaluation of Political Beliefs," 765. Vegetti and Mancosu, "The Impact of Political Sophistication and Motivated Reasoning on Misinformation."

Taber and Lodge, "Motivated Skepticism in the Evaluation of Political Beliefs," 767. 
Ill-informed citizens may be less prone to engaging in motivated reasoning on some (though not all) issues, but they are somewhat prone, and they frequently adopt extreme political positions at similar rates to their allegedly less rational, high-information peers. Critics of epistocracy, while not outright denying such facts, fail to recognize their importance. As suggested at the beginning of this section, establishing the superiority of either democratic or epistocratic institutions will involve measuring the differential harmful impact of generally ignorant, moderately rational citizens as against the impact of more highly informed but less rational citizens. Bearing in mind that both sets of citizens display a lot of variety in how they process political information should caution us against too quickly assuming that the psychological data clearly favors one set of institutions over the other.

\subsection{Open Minds Are Overstated}

Last, we should not assume that it is always good when citizens are open minded, nor always bad when they are closed minded. ${ }^{44}$ Ideally, we want citizens to update their beliefs appropriately in light of new evidence. We do not want citizens to constantly modify their views in a haphazard fashion. More obviously, we do not want citizens to change their beliefs when their beliefs track the truth, or when the countervailing evidence they encounter is sufficiently weak or misleading. In such cases, we want citizens whose minds are closed to evidence that would only lead them astray. This is not to deny that open mindedness is never an attitude that we should wish to cultivate among the electorate, but it does suggest that our evaluation of the behavior of purportedly irrational, closed-minded, high-information citizens should be more sensitive to the specifics of the beliefs in question. For some beliefs in some settings, open mindedness and a willingness to change one's mind are virtues; for others, they are vices.

For example, drawing upon Zaller, Hannon notes that less knowledgeable citizens are more responsive to the content of individual elections. ${ }^{45}$ Among other things, less informed voters are more likely to reward incumbent candidates presiding over a strong national economy, more responsive to ideological shifts on the part of candidates, and at least as likely as their better-informed peers to respond positively to presidential success in managing foreign affairs. He further concludes, drawing upon Achen and Bartels, that "the more knowl-

Kruglanski and Boyatzi, “The Psychology of Closed and Open Mindedness, Rationality, and Democracy."

45 Zaller, "Floating Voters in U.S. Presidential Elections, 1948-200o," 166; Hannon, "Are Knowledgeable Voters Better Voters?" 4. 
edgeable voters tended to ignore or downplay the very considerations that are typically viewed as an appropriate basis for electoral choice." ${ }^{46}$

However, a closer look at the manner in which such voters respond to changes in the economy reveals that their behavior may not be rational. Notably, Achen and Bartels are themselves critical of the claim that voters can "reliably form and act upon sensible retrospective judgements at election time." ${ }^{47}$ On their account, voters who reward presidents presiding over strong economies often exemplify a myopic perspective, neglecting to take into consideration their economic welfare over sufficiently long periods of time. Accordingly, the degree to which less informed voters reward (or punish) presidents for the state of the economy is frequently inappropriate. It does not follow from this, of course, that knowledgeable citizens behave appropriately in not responding to economic conditions during election cycles. Still, this merely reinforces the fact that how we evaluate the behavior of citizens who update their beliefs in response to evidence should be more sensitive to the specific details of any given case. Moreover, it highlights once more the occasionally substantial variation in how citizens with different levels of knowledge process political information.

Summing up, then, the significance of the psychological data adverted to by critics of epistocracy is unclear. The standards by which the psychologists judge that citizens are knowledgeable do not always match epistocratic standards. Rather than a simple relationship between the possession of political knowledge and political irrationality, the data in fact reveals a complex interrelationship between levels of political knowledge, attitude extremity, and political irrationality. Lastly, the virtues of a willingness to change one's mind on political issues vary with the subject matter, the evidence prompting the update of beliefs, and more. Consequently, our confidence in the interpretation of the psychological data offered by critics of epistocracy should be undermined. If so, the severity of the problem of epistocratic irrationality is uncertain.

Before moving ahead, it is worth considering the following possible response to the claims advanced in this section. One might think that, given the controversial nature of many epistocratic proposals, the burden of justification lies squarely with epistocrats defending the epistemic superiority of their preferred institutions. Rebutting critical discussions of epistocracy by issuing purely negative critiques in return is not enough to discharge this burden. Instead, a positive defense of epistocratic institutions (as against democratic alternatives) is

Achen and Bartels, Democracy for Realists, 294; Hannon, "Are Knowledgeable Voters Better Voters?" 4.

47 Achen and Bartels, Democracy for Realists, 175; see also Achen and Bartels, "Blind Retrospection." 
required. Applied to the case at hand, while it may be true that the data from political psychology lacks the implications critics of epistocracy claim it has, establishing this does not constitute a positive argument for epistocracy.

However, even if this claim about the burden of justification is correct, this sort of response suffers from two problems. First, it effectively leaves worries grounded in the putative irrationality of politically knowledgeable citizens behind, conceding that current claims of epistocratic irrationality are unsuccessful. In short, one cannot make this concession while at the same time claiming that the critics have successfully undercut the case for epistocracy. To be sure, this too does not constitute a positive argument in favor of epistocracy. However, such a concession is indicative of the fact that, as far as the comparative epistemic performance of both democratic and epistocratic institutions is concerned, it is an open question as to which is superior. As alluded to earlier, for those willing to experiment with novel institutional arrangements, this is important. Such individuals, noting the failure of current arguments to demonstrate the irrationality of epistocracy, ought to consider epistocratic institutions a live option-at least, that is, certain sorts of epistocratic institutions with the ability to overcome any potential problem with epistocratic irrationality.

Second, as we shall see in the next section, the burden of justification has been met for a certain class of epistocratic institutions. Indeed, since there exists much evidence in favor of the superior epistemic performance of certain epistocratic institutions (relative to more democratic alternatives), the burden of justification plausibly lies with critics of these institutions rather than their supporters.

\section{OVERCOMING EPISTOCRATIC IRRATIONALITY}

The previous section provided some reasons to doubt the interpretation of the psychological data appealed to by critics of epistocracy. Suppose, though, that this interpretation is accurate. What follows from this? In this section, I argue that even if their interpretation is accurate it still does not follow that we should reject epistocratic institutions in favor of democratic institutions.

The problem of epistocratic irrationality is more severe when the costs of epistocratic irrationality outweigh the benefits of amplifying the political power of more knowledgeable citizens. ${ }^{48}$ However, some epistocratic institutions will plausibly be able to mitigate the harmful effects of epistocratic irrationality bet-

48 To be clear, such a distribution of costs and benefits would still not establish the superiority of democratic institutions. Even if the problem of epistocratic irrationality is severe, it might be that the problem of political ignorance in democracies is even more severe. 
ter than others. If they can mitigate these effects such that the costs of irrationality are outweighed by the benefits of empowering more knowledgeable citizens, such institutions will still be viable.

I focus on two strategies for epistocrats. First, I explore whether refined selection mechanisms that avoid placing too much power in the hands of irrational citizens could help to ameliorate epistocratic irrationality. I then discuss implementing only those epistocratic institutions that have a reliable track record of outperforming their more democratic counterparts.

\subsection{Refined Selection Mechanisms}

A presupposition that seemingly underlies the problem of epistocratic irrationality is that epistocracies are committed to uncritically using mechanisms that empower more knowledgeable citizens. Since, let us suppose, more knowledgeable citizens are less rational, the virtues of such mechanisms are questionable at best. This presupposition is not unreasonable since proponents of epistocracy often place heavy emphasis on knowledge of politically important factual matters. Still, there is no reason why epistocrats cannot expand their focus to include the sort of epistemic virtues rightly stressed by critics of epistocracy. ${ }^{49}$

How might epistocrats appropriately expand their focus? Recall that the psychological data adduced by critics of epistocracy does not show that all well-informed citizens are irrational, even setting aside the problems discussed in the previous section. It is perhaps true that, on average, better-informed citizens are less rational than ill-informed citizens, but there are exceptions to this general trend. Most notably, some well-informed citizens are also politically rational. Such citizens can form the target for suitably refined epistocratic selection mechanisms. If we could devise ways to identify citizens who are both well-informed and less prone to various forms of political irrationality, we could amplify their political power rather than the political power of well-informed citizens tout court.

The use of such refined selection mechanisms faces two important obstacles. First, one must devise sufficiently precise tests to distinguish between appropriately rational, knowledgeable citizens and their equally knowledgeable but less rational peers. Second, use of the relevant tests must be feasible given the overall

49 Indeed, the importance of such virtues is already recognized by epistocrats, even if they are discussed less often than knowledge of important factual matters. For example, Brennan defends veto council epistocracy at least partly due to the prospect of such a council providing a forum for its members to engage in careful deliberation (Against Democracy, 215-18). Presumably, such careful deliberation is not desirable for its own sake, but for its ability to allow council members to learn from one another, change their minds on certain issues (if necessary), and the like. The veto council, then, provides institutional settings within which attitudes and behaviors associated with political rationality can flourish. 
epistocratic arrangement in question. Questions of feasibility here primarily revolve around the degree to which the tests can be used cheaply and effectively, especially given large numbers of citizens. These two obstacles are not independent. For instance, the most precise tests may be prohibitively costly to use when large numbers of people are involved, and this might count against certain forms of epistocracy. Correlatively, cost-effective tests may not reliably distinguish between the relevant groups of citizens. Epistocrats thus face potential trade-offs between accuracy and cost-effectiveness, with such trade-offs needing to be factored into any overall cost-benefit assessment of epistocratic proposals.

Let us consider an example that helps to highlight the difficulties that epistocrats may face in using refined selection mechanisms. A natural strategy for epistocrats looking to overcome the problem of epistocratic irrationality is to implement a plural voting scheme wherein the most epistemically virtuous citizens receive comparatively more votes than either their ignorant and ill-informed peers or their well-informed but irrational peers. ${ }^{50} \mathrm{~A}$ nice feature of this form of epistocracy is that, in principle, it could accommodate the claim that the latter group of citizens more harmfully impact political outcomes than the former group. Roughly speaking, we have four groups of citizens to consider: (i) ignorant and irrational citizens, (ii) ignorant but more rational citizens, (iii) well-informed but irrational citizens, and (iv) well-informed and rational citizens. Depending on the magnitude of harm ascribed to empowering each group (or the magnitude of expected benefits in the case of the last group), we could allocate numbers of votes accordingly. If well-informed but irrational citizens make worse decisions than ignorant but more rational citizens, we could modify the numbers to diminish the influence of the former. However, the central aim of such a scheme of plural voting would be to amplify the power of the most epistemically virtuous citizens.

However, empowering the right citizens is easier said than done. We must first identify the relevant people. One option to consider is the use of indirect tests of political rationality such as standard measures of cognitive reflection and rationality quotients. ${ }^{51}$ If scoring well on such measures reliably correlates with a propensity to engage with politically contentious issues in a suitably rational manner, such tests may work well as proxies for political rationality. However, if no correlation exists (or if there is an inverse correlation between the relevant traits), use of these indirect tests risks bringing about the very distribution of

50 For more on plural voting, see Brennan, Against Democracy, 211-14; and Mulligan, "Plural Voting for the 21st Century."

51 Frederick, "Cognitive Reflection and Decision Making"; and Stanovich, "The Comprehensive Assessment of Rational Thinking." 
power that critics of epistocracy worry about-namely, one where politically irrational citizens find their political power unduly increased. ${ }^{52}$

Forgoing indirect measures, one might rely upon measures that directly test for political rationality. For instance, we can measure levels of political rationality in the same way that the political psychologists cited by critics of epistocracy measure it. In other words, in addition to examining the degree to which citizens possess knowledge of politically relevant facts, we can assess, among other things, the degree to which they are capable of mitigating confirmation and disconfirmation biases (as well as other cognitive biases), the degree to which they are willing and able to update their beliefs in response to evidence in ways that are incongruent with their prior positions, the degree to which they can fairly and accurately state the strongest case for views they are ideologically opposed to, and so on. Discussing the precise details of such measures will involve empirical concerns that are beyond the scope of this paper. The important point for our purposes is that while such direct measures are far more accurate than indirect measures, their use is likely not feasible for an arrangement such as plural voting, for subjecting large numbers of citizens to these measures is likely too expensive and too time consuming.

Generalizing the preceding discussion, it becomes clear that some forms of epistocracy are more affected by the problem of epistocratic irrationality than others. To a first approximation, forms of epistocracy that involve very large numbers of citizens - up to and including the entire electorate-are most negatively impacted. For example, schemes of restricted suffrage and, as noted, plural voting, are likely not feasible given the problem of epistocratic irrationality and a lack of accurate, cost-effective indirect measures for refined selection mechanisms. At the same time, though, since the cost of utilizing more precise, direct measures of political rationality varies with institutional background, some forms of epistocracy will be able to feasibly make use of them. Roughly put, as we reduce the number of people to which we seek to apply individually costly measures of political rationality, the aggregate cost of using such measures decreases to such an extent that certain epistocratic institutions become correspondingly more feasible.

What forms of epistocracy can avail of these direct measures? To take an example, consider again veto council epistocracy. Recall that under this form of epistocracy a select group of highly competent individuals would constitute an epistocratic council tasked with overseeing the legislative activities of other in-

52 Kahan suggests that there is indeed an inverse correlation between the relevant traits ("Misconceptions, Misinformation, and the Logic of Identity-Protective Cognition"). If this is correct, the use of indirect measures of political rationality may not be feasible whatsoever. 
stitutions. Extremely demanding qualification requirements would be in place to ensure that only the most competent and knowledgeable individuals are admitted. Adding further tests with the aim of preventing politically irrational agents from joining the council would yield higher feasibility costs compared to a veto council without these tests. Importantly, though, the relatively low numbers involved ensures that veto council epistocracy has much lower aggregate feasibility costs than arrangements like plural voting or restricted suffrage epistocracy. While the latter arrangements employ significantly simpler qualification requirements, the massive number of tests required drives the feasibility costs up. In contrast, the veto council has lower total feasibility costs even though it uses relatively sophisticated qualification requirements. For veto council epistocracy, then, further tests to distinguish between prospective council members of varying levels of rationality are not the drawback they were for epistocracies with higher feasibility costs. Accordingly, the use of refined selection mechanisms provides the veto council with a plausible tool to mitigate the problem of epistocratic irrationality.

Something similar is true of other epistocratic institutions aiming to increase the political influence of relatively low numbers of individuals. For instance, the enfranchisement lottery, wherein a descriptively representative random sample of the population is selected in order to engage in competence-building exercises so that they become better-informed about ballot options, could easily be tweaked to accommodate concerns regarding epistocratic irrationality. ${ }^{53}$ Rather than competence-building exercises alone, descriptively random samples of the population could be subjected to additional screening to ensure that only appropriately rational citizens are furnished with voting rights. For another, consider rule by simulated oracle. ${ }^{54}$ Under this arrangement, we simulate what the electorate would prefer if they were fully informed about important politically relevant facts. Oversimplifying somewhat, we achieve this by surveying citizens' political preferences together with their demographic information, as well as testing their political knowledge. We can then simulate what their preferences would be if we simulated full knowledge while holding the rest of their demographics fixed. A natural modification to such an institution, then, is to use the same method to simulate political preferences given full information and high levels of political rationality.

Summing up, then, while the problem of epistocratic irrationality threatens some epistocratic institutions, others are much less threatened. Restricted suffrage and plural voting may not be feasible, but institutions such as the veto

53 For more on the enfranchisement lottery, see López-Guerra, Democracy and Disenfranchisement, 4; and Brennan, Against Democracy, 214-15.

54 Brennan, Against Democracy, 220-22; Ahlstrom-Vij, "The Case for Modelled Democracy." 
council, enfranchisement lottery, and even rule by simulated oracle can be readily modified to better avoid increasing the power of knowledgeable but irrational citizens. $^{55}$

\subsection{Conservative Epistocratic Institutions}

Refined selection mechanisms provide a potentially useful tool for epistocrats seeking to safeguard more radical epistocratic proposals against the harms of widespread epistocratic irrationality. But there are easier ways to increase the likelihood that the costs of epistocratic irrationality are outweighed by the benefits of empowering more knowledgeable people. Instead of opting for controversial institutional reforms, we could adjust existing institutions in ways that have a good track record of improving performance. In the same vein, we could protect currently successful institutions where disproportionate levels of political power are already placed in the hands of more knowledgeable people. These sorts of conservative epistocratic proposals either modify existing institutions in an epistocratic direction or prevent the modification of existing institutions in less epistocratic directions.

By "conservative," I mean to stress the sense in which these proposals are either manifestations of institutions we already have experience with or are significantly influenced by such institutions. Specifically, these are institutions that have a track record of good performance (relative to some non-epistocratic alternative). Consider the difference between a plural voting scheme utilizing refined selection mechanisms and, say, requiring that civil servants possess certain qualifications. Transitioning from democratic institutions with universal and equal suffrage to plural voting is risky, at least in part owing to uncertainty surrounding the efficacy of such an institution. We may have suggestive indirect evidence bearing on the prospective performance of plural voting, but we can point to very few concrete exemplars with an actual track record we can examine. ${ }^{56}$ In contrast, requiring that civil servants possess certain qualifications relevant to the role they occupy is conservative in the sense that we have concrete evidence bearing on the importance of qualifications. If one were to measure the performance of civil engineers with legitimate engineering credentials against

Additionally, forms of limited epistocracy empowering a relatively low number of experts in narrowly circumscribed roles could feasibly avail of precise and costly measures of political rationality. On limited epistocracy, see Jeffrey, "Limited Epistocracy and Political Inclusion." Plural voting schemes of different sorts have historically been adopted by several countries, including the United Kingdom, New Zealand, and the Republic of Ireland. But it is important to note that these forms of plural voting were not identical to the sorts of plural voting defended by contemporary epistocrats, let alone epistocracy with refined selection mechanisms. Their evidential import is thus unclear. 
the performance of civil engineers without such credentials, one would quickly see the virtues of qualification requirements that are, strictly speaking, epistocratic constraints on access to civil service positions.

Conservative epistocratic institutions of this sort have recently been defended by Garret Jones. ${ }^{57}$ For example, drawing on a wide range of data from political science, he argues that independent central banks typically outperform central banks more tightly constrained by democratic politics. Independent central banks are more reliably correlated with low rates of inflation, low and stable rates of unemployment, steady economic growth, fewer financial crises, and more. ${ }^{58}$ Maintaining the independence of central banks is epistocratic to the extent that insulation from democratic politics allows members of the central bank to draw upon their expertise in a more consistent fashion than would be possible if they were subject to pressure from the electorate, representatives of the electorate, and so on. Epistocrats, then, may wish to protect currently independent central banks from modification in less epistocratic directions. Alternatively, they may urge states without independent central banks to move in an epistocratic direction. ${ }^{59}$

Jones defends other institutions on similar grounds. For example, he argues that appointed, epistocratic city treasurers typically outperform elected treasurers, doing a better job of managing their city's finances. ${ }^{60}$ Moreover, he suggests that the virtues of such institutions provide us with a blueprint for creating novel epistocratic institutions. Drawing on work from Maskin and Tirole, he writes that "when it is crucial to get the technical details right and when the policy debate is less about values and more about facts and competent execution, that is a likely a good opportunity to delegate power to unelected bureaucrats. ${ }^{61}$ For instance, extending the rationale behind maintaining an independent central bank, we could implement a Federal Tax Board. ${ }^{62} \mathrm{~A}$ broad division of labor could exist between Congress (which would decide the broad contours of policy) and the Federal Tax Board (which would focus on the precise details). Implementation of such a novel epistocratic institution is certainly less conservative than main-

57 Jones, $10 \%$ Less Democracy.

58 Jones, $10 \%$ Less Democracy, 41-62.

59 One may think that having no central bank whatsoever is better than having either an independent central bank or a central bank constrained by democratic politics (Rothbard, The Case Against the Fed). But this is consistent with thinking that if we are to have a central bank, then we should have an independent central bank. In such a case, the epistocratic institution is still preferable to the democratic institution on instrumental grounds, even if there is an instrumental justification for abolishing the institution entirely.

60 Jones, $10 \%$ Less Democracy, $76-80$.

61 Maskin and Tirole, "The Politician and the Judge"; and Jones, 10\% Less Democracy, 91-92.

62 Jones, 10\% Less Democracy, 93-94. See also Blinder, Advice and Dissent. 
taining the independence of an already independent central bank. But it is much less radical than, say, transitioning to a political arrangement characterized by use of the enfranchisement lottery since there is already much evidence that institutions of the former sort can outperform democratic alternatives.

For the purposes of this paper, we can remain silent on whether Jones correctly assesses the relevant data. The important point is that opting only for conservative epistocratic institutions offers a simple way for epistocrats to overcome the problem of political irrationality. This claim immediately raises two separate questions. First, what sorts of conservative institutions count as epistocratic? Second, and more important, in what way do these institutions help overcome the problem of epistocratic irrationality?

Regarding the first question, let us count as epistocratic any institution that makes the possession of knowledge or expertise an official requirement of occupying certain roles. According to this account, many existing institutions are epistocratic even if not widely recognized as such. For instance, limits to universal suffrage withholding the right to vote from children are epistocratic to the extent that they are defended on the grounds that children (especially young children) lack sufficient knowledge or judgment to vote competently. ${ }^{63}$ Similarly, members of the judiciary are subject to epistocratic constraints given that jurisprudential expertise is a legal requirement for attaining the relevant positions. Conservative epistocratic reforms, then, might often take the form of implementing these sorts of relatively uncontroversial institutions (or, alternatively, safeguarding them against those who would wish to remove epistocratic constraints).

Regarding the second question, conservative epistocratic institutions undermine the problem of epistocratic irrationality because there is much evidence suggesting that the relevant institutions outweigh the costs associated with epistocratic irrationality. In a sense, reliance upon conservative institutions builds in a response to the problem of epistocratic irrationality from the outset, since this problem trades on the prospect of the costs outweighing the benefits. This is not to say that conservative institutions will always be superior to more radical ones such as plural voting, the veto council, and so on. But conservative institutions can be defended in a less speculative fashion. In addition to epistocracies using refined selection mechanisms with low feasibility costs, then, conservative epistocratic institutions provide a relatively clear way for epistocrats to rebut worries revolving around epistocratic irrationality-they simply outperform their democratic counterparts, even if more knowledgeable citizens tend to be less rational than less knowledgeable citizens.

63 Brennan, "The Right to a Competent Electorate," 701. 
Before moving on, two further clarifications are in order. First, the class of conservative epistocratic institutions can shift over time as more evidence is gathered regarding the efficacy of different institutions. If epistocratic councils were to be formed in many different countries, and if such councils were to perform well, they could eventually be classified as conservative in the relevant sense. As evidence of their solid performance mounts, it would become correspondingly less risky to consider implementing them.

Second, conservative proposals are not necessarily proposals to modify institutions incrementally (or proposals to prevent the incremental modification of existing institutions in less epistocratic directions). In general, institutional reform might take place in increments - that is, by slight adjustments along the margins of existing institutions. Whether a given adjustment counts as incremental is vague, but one can point to clear instances of incremental adjustments as against non-incremental adjustments. Intensifying the qualification requirements for access to certain civil service positions is an incremental adjustment, while the abolition of universal suffrage is not. In practice, conservative epistocratic reform will often be incremental. Incremental adjustments may be easier to attempt, and it may subsequently be easier to develop a body of evidence about their performance. But in principle we could have solid evidence about wide-ranging epistocratic reforms. If so, these non-incremental reforms would properly be described as conservative in the sense outlined earlier. If conservative epistocratic reforms tend to be incremental, this at most reflects a contingent fact about what sorts of reforms people are typically willing to attempt.

\section{OBJECTIONS AND REPLIES}

In this section, I address some objections to the claims defended in previous sections. First, one might worry that empowering collections of individually rational agents may not translate to collectively rational group decision-making. If groups constituted by individually rational agents can behave irrationally, then even epistocracy with refined selection mechanisms might not solve the problem of epistocratic irrationality. Second, one might worry that the problem of epistocratic irrationality can only be solved by epistocratic institutions that would create or exacerbate other more serious problems. If so, epistocratic institutions should not be implemented.

\subsection{Epistocracy and the Independence Thesis}

Individual and group rationality can pull apart. Individually irrational agents can form rational groups, and individually rational agents can form irrational groups. 
Call this the Independence Thesis. ${ }^{64}$ For example, individual scientists who dogmatically defend certain theories can help ensure that good theories remain within the wider scientific community. ${ }^{65}$ This, in turn, might help the scientific community ultimately converge on the truth. By analogy, perhaps a political decision-making body constituted by individually irrational agents can somehow outperform one constituted by individually rational agents.

The Independence Thesis complicates the process of creating epistemically well-functioning groups, in politics and elsewhere. One cannot simply gather a collection of individually rational agents and subsequently guarantee collectively rational decision-making. One must also pay attention to the group's internal structure, its dynamics, and more. Consequently, the case for using refined epistocratic selection mechanisms becomes considerably more complex since we cannot be sure that the eventual group of individually rational (and well-informed) agents will behave in collectively rational ways. If that is right, then we should be less confident in the ability of refined selection mechanisms to overcome the problem of epistocratic irrationality.

Though programmatic, this sort of objection is undeniably important. If epistocrats are serious about designing epistemically well-functioning institutions, they must consider the internal structure and group dynamics of the relevant decision-making bodies they seek to implement. With that said, there are at least three important qualifications one must bear in mind regarding such an appeal to the Independence Thesis.

First, the Independence Thesis does not say that no decision-making body constituted by individually rational agents can behave in collectively rational ways. Nor does it say that no epistocratic institution can outperform any democratic institution. Instead, it tells us that individual and group rationality pull apart. It cautions us against thinking that when we have a collection of individually rational agents, we thereby have a group of agents that will together behave rationally. But whether any given group is in fact organized in epistemically optimal ways is an empirical question. We should not assume that refined selection mechanisms will automatically yield rational groups, to be sure, but we also should not assume that we cannot successfully use refined selection mechanisms to mitigate the problem of epistocratic irrationality.

64 Mayo-Wilson, Zollman, and Danks, “The Independence Thesis." There are in fact several different formulations of the underlying insight that individual and group rationality can diverge. Strictly speaking, then, there is no single independence thesis (Mayo-Wilson, Zollman, and Danks, "The Independence Thesis," 655). I set aside this complication moving forward, writing of the independence thesis for convenience.

Zollman, "The Epistemic Benefit of Transient Diversity." 
Second, an epistocratic tu quoque - much as the independence thesis complicates the case for epistocracy with refined selection mechanisms, it complicates the case against epistocracy grounded in the problem of epistocratic irrationality. The force of the problem of epistocratic irrationality lies in the fact that much psychological research seemingly indicates that the sort of well-informed citizens who would be empowere by epistocratic institutions are also typically less rational than their ill-informed peers. However, per the Independence Thesis, groups of individually irrational agents can constitute collectively rational groups. Individually irrational and knowledgeable citizens might constitute epistemically well-functioning groups despite their individual epistemic vices. Critics of epistocracy appealing to the Independence Thesis, then, undermine the case for refined selection mechanisms at the cost of undermining their initial critique.

Third, and more positively, conservative epistocratic institutions are not subject to this worry. At the very least, this sort of worry is much less serious for conservative epistocratic institutions. By stipulation, we can already be reasonably confident that the relevant institutions strike an appropriate balance between individual and group rationality. At the very least, we can be reasonably confident that conservative epistocratic institutions do a better job of striking such a balance than their democratic counterparts. If no such institutions existed, then the Independence Thesis would be much more troublesome for epistocrats. But since we can find examples of conservative epistocratic institutions, then at least some epistocratic institutions remain viable.

Ultimately, then, the appeal to the Independence Thesis fails. For use of refined selection mechanisms, it is inconclusive, at most suggesting that we ought to be cautious in assuming that group rationality will emerge from the interaction of individually rational agents. For conservative epistocratic institutions, we can already be confident that group rationality does indeed emerge from the interactions of the agents constituting the relevant group, at least to a certain extent.

\subsection{The Problem of Unintended Consequences}

To be fully successful, political institutions designed to solve certain problems need to avoid creating or exacerbating comparably severe (or even worse) problems. An anti-corruption agency with exorbitantly high operational costs, even if it functions as intended, might be a net cost if the funds allocated to its operation could have been better used elsewhere. ${ }^{66}$ Along the same lines, epistocratic institutions with the means to overcome the problem of epistocratic irrationality

66 In general, the optimal level of corruption in any given society might be nonzero. Cf. Klitgaard, Controlling Corruption. 
might solve that problem only while creating or exacerbating others. If the costs of these other problems exceed the benefits of the relevant epistocratic institutions, we should deem these institutions failures, even if they successfully tackle the problem they were designed to tackle.

For instance, suppose that a veto council can successfully overcome the problem of epistocratic irrationality, with its low feasibility costs allowing it to deploy highly multifaceted selection mechanisms. But suppose further that this council would increase risks of abuse and corruption that, in expectation, outweigh the expected gains. ${ }^{67}$ If so, we ought not implement the veto council. Taken in isolation, the institution is a success, performing its function as intended. But when its overall impact on the larger political arrangement of which it is a part is considered, it is a failure. It worsens other problems, even if unintentionally.

Like the previous appeal to the Independence Thesis, this objection is at best inconclusive. Whether potential complications would arise, even with epistocratic institutions well-equipped to overcome the problem of epistocratic irrationality, is an empirical question. At most, it again counsels us to adopt a cautious approach to the implementation of novel political institutions. However, this is - or ought to be-a perfectly general point. The expected complications of novel institutions need to be factored into their overall assessment of whether they are epistocratic or democratic, and we should proceed with caution if uncertain about the downstream negative consequences of implementing them.

Moreover, and again like the previous objection, this worry is most serious for nonconservative epistocratic proposals for which there is uncertainty regarding their efficacy. But conservative epistocratic institutions are precisely those institutions for which we have some evidence of their merits. Since we have evidence of the expected performance of these institutions, in some cases we can be confident that they will not create or exacerbate problems to such an extent that the gains from mitigating epistocratic irrationality are outweighed by the costs. There may indeed be costs associated with civil service qualification requirements, independent central banks, and the like, but the evidence suggests that these costs are outweighed by various gains.

The problem of unintended consequences does not show that epistocratic

67 Vandamme, "What's Wrong with an Epistocratic Council?" Two complications are omitted here as they are beyond the scope of this paper. First, that the veto council might increase the risk of various political abuses is simply taken for granted to illustrate a wider point, namely, that institutions may have unintended consequences that militate against their implementation. Second, I ignore the possibility that epistocratic institutions could be modified to avoid political abuse. Though I cannot defend the claim here, I think that worries about the potential abuse of epistocratic institutions are often overstated, especially given the possibility of modifications that could be made to such institutions to prevent abuse. 
institutions are infeasible. For nonconservative proposals, it shows at most that we should be cautious about implementing them. Conservative epistocratic institutions, as before, bypass this problem. We can already be confident that they do not create negative unintended consequences that outweigh their expected benefits.

\title{
5. CONCLUSION
}

Epistocrats perhaps reasonably worry about high levels of political ignorance among voters. But their critics reasonably observe in turn that increasing the political power of those citizens who possess more knowledge is not guaranteed to constitute an improvement over the status quo. If these citizens also happen to be much less rational than their ignorant peers, epistocratic reforms might just make things worse.

It is important in that regard to get clear on what the data from political psychology shows. As argued in section 2, critics of epistocracy overstate the degree to which the relevant findings establish that different epistocratic institutions would empower irrational citizens in harmful ways. More crucially, though, critics of epistocracy have overlooked the possibility that certain incarnations of epistocracy could overcome the problem of epistocratic irrationality entirely, even if the relevant psychological data has the implications that critics claim it has. Perhaps more refined epistocratic selection mechanisms could allow us to screen for irrational citizens, provided the feasibility costs of using such mechanisms are sufficiently low. Perhaps we could play it safe, opting to implement or preserve conservative institutions with a track record of solid performance. Perhaps both could be pursued in tandem. Whatever the case, epistocrats have viable strategies for mitigating the problem of epistocratic irrationality.

On balance, then, while critics of epistocracy have alerted us to potential complications that could arise upon transitioning to some form of epistocracy, they have not shown that all forms of epistocracy are equally suspect. The problem of epistocratic irrationality, if it is indeed a problem, can be overcome. ${ }^{68}$

\author{
Rutgers University \\ adam.gibbons@rutgers.edu
} versity and the Forethought Foundation, and two anonymous referees for their feedback on this paper. 
Abramowitz, Alan I., and Kyle L. Saunders. "Is Polarization a Myth?” Journal of Politics 70, no. 2 (April 2008): 542-55.

Achen, Christopher H., and Larry Bartels. "Blind Retrospection: Electoral Responses to Drought, Flu, and Shark Attacks." Presentation at the Annual Meeting of the American Political Science Association, Boston, 2002.

- Democracy for Realists: Why Elections Do Not Produce Responsive Government. Princeton: Princeton University Press, 2016.

- "It Feels Like We're Thinking: The Rationalizing Voter and Electoral Democracy." Presentation at the Annual Meeting of the American Political Science Association, Philadelphia, 2006.

Ahlstrom-Vij, Kristoffer. "The Case for Modelled Democracy." Episteme (forthcoming). Published ahead of print, May 6, 2020. https://doi.org/10.1017/ epi.2020.10.

Bartels, Larry. Unequal Democracy: The Political Economy of the New Gilded Age. Princeton: Princeton University Press, 2008.

Blinder, Alan. Advice and Dissent: Why America Suffers When Economics and Politics Collide. New York: Basic Books, 2018.

Bolsen, Toby, James N. Druckman, and Fay Lomax Cook. "The Influence of Partisan Motivated Reasoning on Public Opinion." Political Behavior 36, no. 2 (June 2014): 235-62.

Box-Steffensmeier, Janet M., and Suzanna De Boef. "Macropartisanship and Macroideology in the Sophisticated Electorate." Journal of Politics 63, no. 1 (February 2001): 232-48.

Brennan, Jason. Against Democracy. Princeton: Princeton University Press, 2016. -. "The Right to a Competent Electorate." Philosophical Quarterly 61, no. 245 (October 2011): 700-24.

Caplan, Bryan. The Myth of the Rational Voter: Why Democracies Choose Bad Policies. Princeton: Princeton University Press, 2007.

Converse, Philip. “The Nature of Belief Systems in Mass Publics.” In Ideology and Discontent, edited by David Apter, 206-61. New York: Free Press, 1964.

Dewey, John. Democracy and Education. New York: Macmillan, 1916.

Federico, Christopher M. "Predicting Attitude Extremity: The Interactive Effects of Schema Development and the Need to Evaluate and Their Mediation by Evaluative Integration." Personality and Social Psychology Bulletin 30, no. 10 (October 2004): 1281-94.

Feldman, Lauren, and Vincent Price. "Confusion or Enlightenment? How Exposure to Disagreement Moderates the Effects of Political Discussion and 
Media Use on Candidate Knowledge." Communication Research 35, no. 1 (February 2008): 61-87.

Frederick, Shane. "Cognitive Reflection and Decision Making." Journal of Economic Perspectives 19, no. 4 (Fall 2005): 25-42.

Friedman, Jeffrey. "Democratic Competence in Normative and Positive Theory: Neglected Implications of 'The Nature of Belief Systems in Mass Publics.” Critical Review 18, nos. 1-3 (2006): 1-43.

- Power without Knowledge: A Critique of Technocracy. Oxford: Oxford University Press, 2019.

Gibbons, Adam F. "Political Disagreement and Minimal Epistocracy." Journal of Ethics and Social Philosophy 19, no. 2 (February 2021): 192-201.

Goodin, Robert E., and Kai Spiekermann. An Epistemic Theory of Democracy. Oxford: Oxford University Press, 2018.

Guay, Brian, and Christopher Johnston. "Ideological Asymmetries and the Determinants of Politically Motivated Reasoning." American Journal of Political Science (forthcoming). Published ahead of print, June 23, 2021. https://doi. org/10.1111/ajps.12624.

Guerrero, Alexander A. "Against Elections: The Lottocratic Alternative." Philosophy and Public Affairs 42, no. 2 (Spring 2014): 135-78.

Gunn, Paul. "Against Epistocracy." Critical Review 31, no. 1 (2019): $26-82$.

Gutmann, Amy. Democratic Education. Princeton: Princeton University Press, 1999.

Gutmann, Amy, and Dennis F. Thomson. Why Deliberative Democracy? Princeton: Princeton University Press, 2004.

Haidt, Jonathan. The Righteous Mind: Why Good People Are Divided by Politics and Religion. London: Penguin Books, 2012.

Hannon, Michael. “Are Knowledgeable Voters Better Voters?” Politics, Philosophy and Economics (forthcoming). Published ahead of print, January 10, 2022. https://doi.org/10.1177/1470594X211065080.

Hartman, Todd K., and Adam J. Newmark. "Motivated Reasoning, Political Sophistication, and Associations between President Obama and Islam." Political Science and Politics 45, no. 3 (July 2012): 449-55.

Hetherington, Marc J. "Putting Polarization in Perspective." British Journal of Political Science 39, no. 2 (April 2009): 413-48.

Jarvis, W. Blair G., and Richard E. Petty. "The Need to Evaluate." Journal of Personality and Social Psychology 70, no. 1 (1996): 172-94.

Jeffrey, Anne. "Limited Epistocracy and Political Inclusion." Episteme 15, no. 4 (December 2018): 412-32. 
Jones, Garett. 10\% Less Democracy: Why You Should Trust the Elites a Little More and the Masses a Little Less. Stanford: Stanford University Press, 2020.

Joslyn, Mark R., and Donald P. Haider-Markel. "Who Knows Best? Education, Partisanship, and Contested Facts." Politics and Policy 42, no. 6 (December 2014): 919-47.

Judd, Charles M., and Markus Brauer. "Repetition and Evaluative Extremity." In Attitude Strength: Antecedent and Consequences, edited by Richard E. Petty and Jon A. Krosnick, 43-72. Mahwah, NJ: Lawrence Erlbaum, 1995.

Kahan, Dan M. "Misconceptions, Misinformation, and the Logic of Identity-Protective Cognition." Cultural Cognition Project Working Paper Series, no. 164. http://ssrn.com/abstract $=2973067$.

Kahan, Dan M., Ellen Peters, Erica Dawson, and Paul Slovic. "Motivated Numeracy and Enlightened Self-Government." Behavioral Public Policy 1, no. 1 (2017): 54-86.

Kalmoe, Nathan P. "Uses and Abuses of Ideology in Political Psychology." Political Psychology 41, no. 4 (August 2020): 771-93.

Klitgaard, Robert. Controlling Corruption. Berkeley: University of California Press, 1988.

Kruglanski, Arie W., and Lauren M. Boyatzi. "The Psychology of Closed and Open Mindedness, Rationality, and Democracy." Critical Review 24, no. 2 (2012): 217-32.

Kunda, Ziva. “The Case for Motivated Reasoning." Psychological Bulletin 108, no. 3 (November 1990): 480-98.

Kuru, Ozan, Josh Pasek, and Michael W. Traugott. "Motivated Reasoning in the Perceived Credibility of Public Opinion Polls." Public Opinion Quarterly 81, no. 2 (Summer 2017): 422-46.

Landemore, Hélène. Democratic Reason: Politics, Collective Intelligence, and the Rule of the Many. Princeton: Princeton University Press, 2013.

Lodge, Milton, and Charles S. Taber. The Rationalizing Voter. Cambridge: Cambridge University Press, 2013.

López-Guerra, Claudio. Democracy and Disenfranchisement: The Morality of Electoral Exclusions. New York: Oxford University Press, 2014.

Malcolm, Finlay. "Epistocracy and Public Interests." Res Publica (forthcoming). Published ahead of print, June 17, 2021. https://doi.org/10.1007/s11158-021 -09502-7.

Maskin, Eric, and Jean Tirole. "The Politician and the Judge: Accountability in Government.” American Economic Review 94, no. 4 (September 2004): 103454 . 
Mason, Lilliana. Uncivil Agreement: How Politics Became Our Identity. Chicago: University of Chicago Press, 2018.

Mayo-Wilson, Conor, Kevin J.S. Zollman, and David Danks. "The Independence Thesis: When Individual and Social Epistemology Diverge." Philosophy of Science 78, no. 4 (October 2011): 653-77.

Mill, John Stuart. Considerations on Representative Government. LaVergne, TN: Book Jungle, 2010.

Mulligan. Thomas. "Plural Voting for the 21st Century." Philosophical Quarterly 68, no. 271 (April 2018): 286-306.

Oppenheimer, Danny, and Mike Edwards. Democracy Despite Itself: Why a System That Shouldn't Work at All Works So Well. Cambridge, MA: MIT Press, 2012.

Rothbard, Murray N. The Case Against the Fed. Auburn, AL: The Ludwig von Mises Institute, 1994.

Shani, Danielle. "Knowing Your Colors: Can Knowledge Correct for Partisan Bias in Political Perceptions?" Annual Meeting of the Midwest Political Science Association, 2006.

Somin, Ilya. Democracy and Political Ignorance: Why Smaller Government Is Smarter. Stanford: Stanford University Press, 2013.

Stanovich, Keith E. "The Comprehensive Assessment of Rational Thinking." Educational Psychologist 51, no. 1 (2016): 23-34.

Surowiecki, James. The Wisdom of Crowds. New York: Anchor Books, 2005.

Taber, Charles S., Damon Cann, and Simona Kucsova. "The Motivated Processing of Political Arguments." Political Behavior 31, no. 2 (June 2009): 137-55.

Taber, Charles S., and Milton Lodge. "Motivated Skepticism in the Evaluation of Political Beliefs." American Journal of Political Science 50, no. 3 (July 2006): 755-69.

Vandamme, Pierre-Étienne. "What's Wrong with an Epistocratic Council?” Politics 40, no. 1 (2019): 90-105. https://doi.org/10.1177/0263395719836348.

Vegetti, Federico, and Moreno Mancosu. "The Impact of Political Sophistication and Motivated Reasoning on Misinformation." Political Communication 37, no. 5 (2020): 678-95.

Zaller, John. "Floating Voters in U.S. Presidential Elections, 1948-200o." In Studies in Public Opinion: Attitudes, Nonattitudes, Measurement Error, and Change, edited by Willem E. Saris and Paul M. Sniderman, 166-214. Princeton: Princeton University Press, 2004.

Zollman, Kevin J. S. “The Epistemic Benefit of Transient Diversity." Erkenntnis 72, no. 1 (January 2010): 17-35. 